\title{
A new methodology for in-flight radiometric calibration of the MIVIS imaging sensor
}

\author{
Marco Gianinetto and Giovanmaria Lechi \\ Laboratorio di Telerilevamento, Dipartimento di Ingegneria, Idraulica, Ambientale, \\ Infrastrutture Viarie, Rilevamento (DIIAR), Politecnico di Milano, Italy
}

\begin{abstract}
Sensor radiometric calibration is of great importance in computing physical values of radiance of the investigated targets, but often airborne scanners are not equipped with any in-flight radiometric calibration facility. Consequently, the radiometric calibration or airborne systems usually relies only on pre-flight and vicarious calibration or on indirect approaches. This paper introduces an experimental approach that makes use of on-board calibration techniques to perform the radiometric calibration of the CNR's MIVIS (Multispectral Infrared and Visible Imaging Spectrometer) airborne scanner. This approach relies on the use of an experimental optical test bench originally designed at Politecnico di Milano University (Italy), called MIVIS Flying Test Bench (MFTB), to perform the first On-The-Fly (OTF) calibration of the MIVIS reflective spectral bands. The main task of this study is to estimate how large are the effects introduced by aircraft motion (e.g., e.m. noise or vibrations) and by environment conditions (e.g., environment temperature) on the radiance values measured by the MIVIS sensor during the fly. This paper describes the first attempt to perform an On-The-Fly (OTF) calibration of the MIVIS reflective spectral bands (ranging from $430 \mathrm{~nm}$ to $2.500 \mathrm{~nm}$ ). Analysis of results seems to point out limitations of traditional radiometric calibration methodology based only on pre-flight approaches, with important implications for data quality assessment.
\end{abstract}

Key words hyperspectral - airborne scanner MIVIS - radiometric calibration - data quality

\section{Introduction}

The uncertainty introduced by the retrieval methods of remotely sensed measurements is related both to sensor calibration and its stability, as well as to atmospheric effects. As a matter of fact, the problem of data calibration has become a key problem for many remote sensing applications. The main task of the calibration process is

Mailing address: Dr. Marco Gianinetto, Laboratorio di Telerilevamento, Dipartimento di Ingegneria, Idraulica, Ambientale, Infrastrutture Viarie, Rilevamento (DIIAR), Politecnico di Milano, Piazza L. Da Vinci 32, 20133 Milano, Italy; e-mail: gianinetto@polimi.it to experimentally determine the relationship between the measured signals, expressed as instrumental counts, and the corresponding physical values of radiance of the investigated targets, and it has to guarantee the reliability and reproducibility of the measured object radiances not only in the laboratory but also throughout the mission. The methods used for sensor calibration can be grouped into three domains (Dinguirard and Slater, 1999): pre-launch, in-flight and indirect or vicarious approaches.

As many authors stated (Teillet et al., 1997; Thome, 2002), to derive high quality data from remote sensed images, sensors must be time-stable instruments with well-understood characteristics. Therefore, it is always a good norm to include calibration approaches that are independent from pre-flight in research programs. Traditionally, the radiometric calibration of satellite systems has been accomplished by on-board calibration 
sources (such as lamps, diffusers, etc.) supported by vicarious calibration activities using natural targets, while nowadays several sensors are using the moon (Barnes et al., 1999; Kieffer and Wildey, 1996) or stellar targets (Bowen, 2002) as calibration references. Unfortunately, most of the airborne sensors are not equipped with any inflight radiometric calibration device. For this reason, the calibration procedure of airborne systems usually relies only on pre-flight and indirect approaches that cannot assess the real performance of the sensor during the fly.

This paper introduces an experimental approach that makes use of on-board calibration techniques to perform the radiometric calibration of CNR's MIVIS (Multispectral Infrared and Visible Imaging Spectrometer) airborne scanner. This approach relies on the use of an experimental optical test bench originally designed at the Remote Sensing Laboratory of the Politecnico di Milano University (Italy), called MIVIS Flying Test Bench (MFTB), to perform the first on-thefly (OTF) calibration of the MIVIS reflective spectral bands. The OTF of the MIVIS sensor was performed with a 1-h in-flight ATP (Acceptance Test Procedure), using the MFTB as reference source mounted onto the MIVIS scan head. By rationing the digital numbers (DNs) output from the MIVIS with the laboratory measured radiance of the optical test bench, the absolute OTF radiometric calibration of the MIVIS hyperspectral scanner was achieved.

The main task of this study was to estimate how large were the effects introduced by aircraft motion (e.g., noise, vibrations) and by operational conditions (e.g., environment temperature) on radiance values measured by the MIVIS hyperspectral scanner, and also to verify the temporal stability of the MIVIS sensor during the fly. All this to improve the radiometric calibration of MIVIS data.

A brief overview of the MFTB calibrator and first results of the MIVIS OTF calibration tests are presented.

\section{The MIVIS sensor}

The MIVIS is an airborne hyperspectral scanner for remote sensing applications belong- ing to Italian CNR-IIA, Roma. The MIVIS optical system consists of a scanner and four spectrometers. Line array detectors are used, requiring scanning to be performed mechanically in whisk broom mode (Bianchi et al., 1995). One spectrometer line detector array exists for each of the visible (VIS), near infrared (NIR), shortwave infrared (SWIR) and thermal infrared (TIR) portions of the spectrum, for a total of 102 spectral bands ranging from $430 \mathrm{~nm}$ to $12.680 \mathrm{~nm}$.

\section{Radiometric calibration of the MIVIS sensor and the MFTB}

The radiometric calibration of the MIVIS hyperspectral scanner is usually done prior to the flight with the optical test bench Daedalus AB532 which was supplied from the manufacturer (Daedalus Enterprises, Ann Arbor, MI, U.S.A.). For VIS, NIR and SWIR calibration (ranging from $430 \mathrm{~nm}$ to $2.500 \mathrm{~nm}$ ) the Daedalus AB532 optical bench uses a white Spectralon (polytetrafloroethylene) panel illuminated under a fix geometrical configuration, while for TIR calibration (ranging from $8.200 \mathrm{~nm}$ to $12.700 \mathrm{~nm}$ ) it uses a blackbody flat plate. The DN to at-sensor-radiance conversion is performed using a self calibration procedure called Acceptance Test Procedure (ATP). In particular, for the 92 reflective bands (spectral bands from no. 1 to no. 92), the ATP measures, for every MIVIS scanning frequency (from $8.3 \mathrm{~Hz}$ to 25 $\mathrm{Hz}$ ), the radiance of the Daedalus AB532 test bench illuminated at constant power (fig. 1).

The limit in using the Daedalus AB532 test bench for deriving the MIVIS radiometric calibration parameters (gains and offsets) is that the Daedalus AB532 test bench is not a transportable device (dimensions: $890 \mathrm{~mm} \times 640 \mathrm{~mm} \times 1200$ $\mathrm{mm}$, weight: $160 \mathrm{~kg}$ ), thus it is not possible to test the scanner's performance during the flight. To estimate how large are the effects introduced by the aircraft motion and environment conditions (e.g., temperature effects) on the radiance values measured by the MIVIS sensor, a very compact and light calibration device was designed to be used for MIVIS OTF radiometric calibration. 


\begin{tabular}{|c|c|c|c|c|c|c|c|}
\hline \multicolumn{8}{|c|}{ Speed: $[6.25] \mathrm{Hz}$} \\
\hline Chn & Band uM & Radiance & Cal & $\operatorname{Ref} 1$ & Noise & NER & NER Rqd \\
\hline 1 & $0.43-0.45$ & $1.02 \mathrm{E}-06$ & 199.8 & 108 & 2.4 & $2.67 \mathrm{E}-08$ & 3. $0 \mathrm{E}-08$ \\
\hline 2 & $0.45-0.47$ & $1.31 \mathrm{E}-06$ & 264.2 & 102 & 2.1 & $1.71 \mathrm{E}-08$ & $3.0 \mathrm{E}-08$ \\
\hline 3 & $0.47-0.49$ & $1.62 \mathrm{E}-06$ & 366.2 & 111 & 2.4 & $1.54 \mathrm{E}-08$ & $2.0 \mathrm{E}-08$ \\
\hline 4 & $0.49-0.51$ & $1.96 \mathrm{E}-06$ & 471.7 & 109 & 2.3 & $1.26 \mathrm{E}-08$ & $2.0 \mathrm{E}-08$ \\
\hline \multicolumn{8}{|c|}{ Speed: $[6.25] \mathrm{Hz}$} \\
\hline Chn & Band uM & Radiance & Cal & Ref 1 & Noise & NER & NER Rqd \\
\hline 5 & $0.51-0.53$ & $2.32 \mathrm{E}-06$ & 330.3 & 82 & 1.6 & $1.46 \mathrm{E}-08$ & $2.0 \mathrm{E}-08$ \\
\hline 6 & $0.53-0.55$ & $2.70 \mathrm{E}-06$ & 400.6 & 83 & 1.6 & $1.32 \mathrm{E}-08$ & $2.0 \mathrm{E}-08$ \\
\hline 7 & $0.55-0.57$ & $3.09 \mathrm{E}-06$ & 479.3 & 78 & 1.5 & $1.19 \mathrm{E}-08$ & $2.0 \mathrm{E}-08$ \\
\hline 8 & $0.57-0.59$ & $3.47 \mathrm{E}-06$ & 569.2 & 91 & 1.8 & $1.34 \mathrm{E}-08$ & $2.0 \mathrm{E}-08$ \\
\hline 9 & $0.59-0.61$ & $3.84 \mathrm{E}-06$ & 661.5 & 88 & 1.7 & $1.12 \mathrm{E}-08$ & $2.0 \mathrm{E}-08$ \\
\hline 10 & $0.61-0.63$ & $4.19 \mathrm{E}-06$ & 734.2 & 88 & 1.7 & $1.08 \mathrm{E}-08$ & 2. $0 \mathrm{E}-08$ \\
\hline 11 & $0.63-0.65$ & $4.53 \mathrm{E}-06$ & 827.6 & 98 & 1.7 & $1.06 \mathrm{E}-08$ & $2.0 \mathrm{E}-08$ \\
\hline 12 & $0.65-0.67$ & $4.85 \mathrm{E}-06$ & 900.0 & 98 & 1.9 & $1.16 \mathrm{E}-08$ & $2.0 \mathrm{E}-08$ \\
\hline 13 & $0.67-0.69$ & $5.15 \mathrm{E}-06$ & 957.3 & 92 & 2.1 & $1.22 \mathrm{E}-08$ & $2.0 \mathrm{E}-08$ \\
\hline 14 & $0.69-0.71$ & $5.42 \mathrm{E}-06$ & 996.7 & 93 & 1.9 & $1.13 \mathrm{E}-08$ & $2.0 \mathrm{E}-08$ \\
\hline 15 & $0.71-0.73$ & $5.66 \mathrm{E}-06$ & 1011.4 & 92 & 1.9 & $1.18 \mathrm{E}-08$ & $2.0 \mathrm{E}-08$ \\
\hline 16 & $0.73-0.75$ & $5.87 \mathrm{E}-06$ & 989.9 & 86 & 1.8 & $1.15 \mathrm{E}-08$ & $2.0 \mathrm{E}-08$ \\
\hline 17 & $0.75-0.77$ & $6.04 \mathrm{E}-06$ & 972.9 & 97 & 1.8 & $1.26 \mathrm{E}-08$ & $2.0 \mathrm{E}-08$ \\
\hline 18 & $0.77-0.79$ & $6.17 \mathrm{E}-06$ & 930.5 & 85 & 1.6 & $1.19 \mathrm{E}-08$ & $2.0 \mathrm{E}-08$ \\
\hline 19 & $0.79-0.81$ & $6.22 \mathrm{E}-06$ & 887.3 & 94 & 1.9 & $1.48 \mathrm{E}-08$ & $2.0 \mathrm{E}-08$ \\
\hline 20 & $0.81-0.83$ & $6.38 \mathrm{E}-06$ & 871.5 & 91 & 1.8 & $1.49 \mathrm{E}-08$ & $2.0 \mathrm{E}-08$ \\
\hline
\end{tabular}

Fig. 1. Example of Acceptance Test Procedure (ATP) self calibration procedure output file for the first 20 MIVIS spectral bands.

The MFTB was designed at Politecnico di Milano University (Italy) and built with the technical support of Compagnia Generale Ripreseaeree (CGR), Parma, Italy (now a Blom ASA Company). The project of the MFTB concerned the definition of physical, optical and radiometric characteristics of the new test bench system, followed by the building of a prototype. The MFTB is composed of two different sub systems: the test bench and the power supply.

The test bench was shaped to fit the MIVIS scan head during the flight and was designed to fit in the aircraft Casa $212 \mathrm{C}$ used to carry the MIVIS $(140 \mathrm{~mm} \times 340 \mathrm{~mm} \times 210 \mathrm{~mm})$. It was built using a $3 \mathrm{~mm}$ aluminium sheet for the external chassis and a $10 \mathrm{~mm}$ white Teflon coat for the internal Lambert diffuser. As light sources, four $10 \mathrm{~W}$ halogen lamps (with colour temperature $2900 \mathrm{~K}$ ) were used, disposed with a symmetrical geometry.
To supply the MFTB both using the $220 \mathrm{~V}$ $\mathrm{AC}$ and the aircraft $28 \mathrm{~V}$ DC, a current controlled power supply with constant output (3.32 A at 12.5 V DC) was built.

\section{Field experiments and preliminary results}

After a laboratory check, the radiance of the MFTB was measured using a laboratory Analytical Spectral Device (ASD) FieldSpec FR spectroradiometer. The ASD was chosen because of its spectral range similar to that of the MIVIS reflected bands (ranging from $350 \mathrm{~nm}$ to 2.500 $\mathrm{nm})$ and its higher sampling frequency $(1.4 \mathrm{~nm}$ at $350-1.000 \mathrm{~nm}$ and $2 \mathrm{~nm}$ at $1.000-2.500 \mathrm{~nm}$ ). Moreover, for the VIS and the NIR bands, the Noise Equivalent Radiance (NER) of the ASD is of one order of magnitude smaller than the NER of the MIVIS, and is of two order of magnitude 
smaller for the SWIR. Therefore, the uncertainties in using the ASD to validate the MFTB calibrator is at least one order of magnitude smaller than the MIVIS precision.

The construction phase of the MFTB was followed by a period of validation tests at CGR, where the intercalibration between the Daedalus AB532 and MFTB optical test benches was achieved on the basis of a traditional laboratory ATPs.

To realize the OTF calibration for the MIVIS sensor, the MFTB was mounted onto the MIVIS scan head and the sensor was flown to perform a 1-h in-flight ATP under controlled conditions (fig. 2). To control the MFTB calibrator stability during the tests, the OTF ATP was carried out controlling the current flowing from the MFTB power supply to the MFTB internal lamps (3.32 $\mathrm{A}$ at $12.5 \mathrm{~V} \mathrm{DC})$.

Concerning the use of the MFTB during the flight, unpredictable differences in at-sensor radiance were found comparing the results of the laboratory calibration tests with those per- formed on-the-fly (fig. 3). While differences in at-sensor radiance measured in the VIS (ranging from $430 \mathrm{~nm}$ to $830 \mathrm{~nm}$ ) are small and limited to $1-2 \%$, in the NIR (ranging from 1.150 $\mathrm{nm}$ to $1.550 \mathrm{~nm}$ ) they grow up to more than $6.5 \%$ for MIVIS spectral band no. 27 (1.450 $\mathrm{nm}-1.500 \mathrm{~nm}$ wavelength) and no. 28 (1.500 $\mathrm{nm}-1.550 \mathrm{~nm}$ wavelength).

Our OTF experiments are in accordance with the differences found in the MIVIS survey of Grado (Italy) in winter 2000 (Giardino et al., 2001), where, after performing on the MIVIS data atmospheric correction with the Second Simulation of Satellite Signal in the Solar Spectrum (6S) radiative transfer code (Vermote et al., 1997), researchers found that the MIVIS NIR data and the ground reference measurements taken with the ASD during the survey diverged of about $10 \%$.

Analysis of results points out the limitations of traditional calibration techniques for airborne sensors. Using a traditional methodology (laboratory test bench or laboratory integrating sphere)

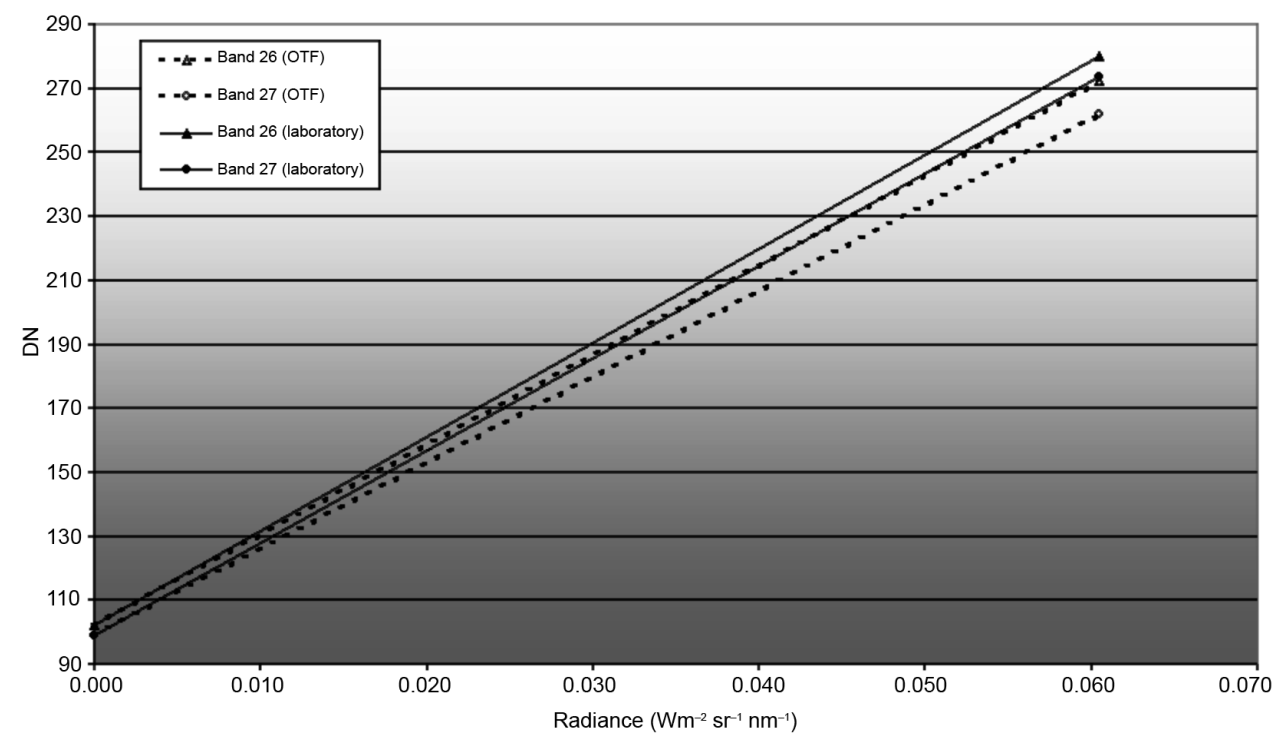

Fig. 2. Relationship between DN and at-sensor-radiance computed with the OTF procedure (OTF) and with the traditional laboratory ATP (laboratory). Comparison of results for the MIVIS spectral bands no. 26 and no. 27 using the MFTB calibrator. 


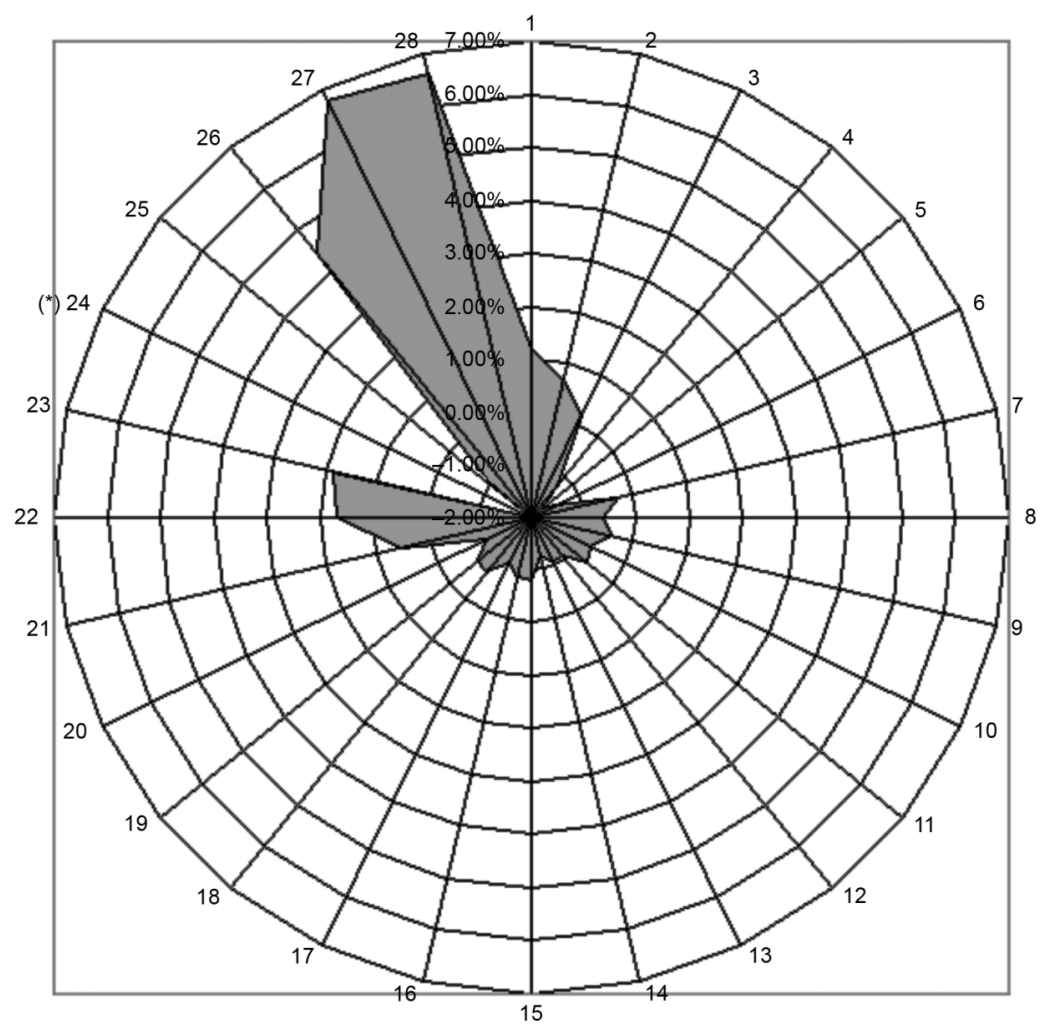

Fig. 3. Comparison between ground tests and OTF tests. Differences in at-sensor-radiance stands out between $1 \%$ and $2 \%$ in the VIS (ranging from $430 \mathrm{~nm}$ to $830 \mathrm{~nm}$ wavelength) and more than $6.5 \%$ in the NIR (ranging from $1.150 \mathrm{~nm}$ to $1.550 \mathrm{~nm}$ wavelength). $(*)=$ spectral band not working during the tests.

for computing the instrumental gain and offset parameters, it is not possible to test the sensor in real conditions. For this reason, a precise data conversion from instrumental counts into radiance values can be only derived in post-processing using on OTF procedure as that here described. As shown in our tests, sometimes these differences can be not negligible and also seems to be wavelength dependant, not only a constant bias.

\section{Conclusions}

For many remote sensing applications the use of calibrated data has become one of the most important points. Besides, the use of a large number of narrow spectral bands forces hyperspectral sensors to have SNR that decreases with increasing wavelength, and this can restrict the real use of hyperspectral data to only visible and near-infrared data, if not adequately calibrated (Colombo et al., 2002).

A new optical test bench for the MIVIS airborne hyperspectral scanner (MFTB) was originally developed at Politecnico di Milano University to improve the use of remote sensed MIVIS data. The new approach to airborne OTF calibration proposed in this paper and the use of the experimental MFTB has shown that MIVIS data may be affected by considerable error if the radiometric conversion procedure is not based on real in-flight conditions, as Giardino et al. (2001) showed with an independent study for Grado (Italy) MIVIS survey. 


\section{Acknowledgements}

This work has been carried out under a research framework founded by Italian National Research Council (CNR), contract title «Calibrazione radiometrica su 102 canali distribuiti fra le bande dal visibile all'infrarosso termico dello scanner iperspettrale aerotrasportato MIVIS del CNR» and by the Italian Space Agency (ASI) within the project «Certificazione di qualità delle mappe tematiche e dei Modelli Digitali delle Elevazioni (DEM) ottenute con tecniche di telerilevamento e standardizzazione di legende, classificatori e caratteristiche spettrali radiometriche e geometriche» contract number I/R/132/01. The MFTB development would not have been possible without the technical support of Compagnia Generale Ripreseaeree, Parma (Italy). In particular, the authors wish to thank L. Ferretti, A. Cavazzini, A. Mantovani and G. Pizzaferri. The remote sensing institute of the CNR-IREA, Milano (Italy) contributed additional technical support regarding measurements with the ASD spectroradiometer. Special thanks go to C. Giardino (CNR-IREA) and M. Lualdi (DIS - Politecnico di Milano University, Italy) for their help in this research.

\section{REFERENCES}

Barnes, R.A., E.E. EpleE, F.S. Patt and C.R. McClain (1999): Changes in the radiometric sensitivity of the
SeaWiFS determined from lunar and solar-based measurements, Appl. Opt., 38, 4649-4664.

Bianchi, R., R.M. Cavalli, L. Fiumi, C.M. Marino and S. PIGNATTI (1995): CNR LARA Project, Italy: airborne laboratory for environmental research, in Proceedings of the Fifth JPL Airborne Earth Science Workshop, 2327 January 1995, Pasadena, U.S.A., 1, 15-18.

Bowen, H.S. (2002): Absolute radiometric calibration of the IKONOS sensor using radiometrically characterized stellar sources, in Proceedings of the Pecora 15/Land Satellite Information IV/ISPRS Commission I/FIEOS 2002 Conference, 10-14 November 2002, Denver, Colorado.

Colombo, A., M. Gianinetto and G. Lechi (2002): Dall'iperspettrale al superspettrale, in Atti della VI Conferenza Nazionale ASITA, 5-8 November 2002, Perugia, Italy.

Dinguirard, M. and P.N. Slater (1999): Calibration of space-multispectral imaging sensors: a review, Remote Sensing Environ., 68 (3), 194-205.

Giardino, C., P.A. Brivio and M. Sgavetti (2001): Effetti della geometria della ripresa e della radianza dell'atmosfera sull'interpretazione di dati MIVIS, AITInforma, Rivista Italiana di Telerilevamento, 20/21, 99-105.

KIEFFER, H.H. and R.L. WILDEY (1996): Establishing the moon as a spectral radiance standard, J. Atmos. Oceanic Technol., 13 (2), 360-375.

TeIllet, P.M., D.N.H. Horler and N.T. O’NeILl (1997): Calibration, validation, and quality assurance in remote sensing: a new paradigm, Can. J. Remote Sensing, 23 (4), 401-414.

Thome, K.J. (2002): Ground looking radiometric calibration approaches for remote sensing imagers in the solar reflective, in Proceedings of the Pecora 15/Land Satellite Information IV/ISPRS Commission I/FIEOS 2002 Conference, 10-14 November 2002, Denver, Colorado.

Vermote, E.F., D. Tanré, J.L. Deuzé, M. Herman and J.J. MorCRETTE (1997): Second simulation of satellite signal in the solar spectrum, 6S: an overview, IEEE Trans. Geosci. Remote Sensing, 35 (3), 675-686. 